\title{
Imaging and analytics on the Helium lon Microscope
}

\author{
Tom Wirtz*, Olivier De Castro, Jean-Nicolas Audinot, Patrick Philipp \\ Advanced Instrumentation for lon Nano-Analytics (AINA), MRT Department, Luxembourg Institute of \\ Science and Technology (LIST), 41 rue du Brill, L-4422 Belvaux, Luxembourg \\ Email addresses: \\ Tom Wirtz: tom.wirtz@list.lu \\ Olivier De Castro: olivier.decastro@list.lu \\ Jean-Nicolas Audinot: jean-nicolas.audinot@list.lu \\ Patrick Philipp: patrick.philipp@list.lu
}

\begin{abstract}
The Helium Ion Microscope (HIM) has emerged as an instrument of choice for patterning, imaging and more recently analytics at the nano-scale. Here, we give an overview on secondary electron imaging on the HIM and review the various methodologies and hardware components that have been developed to confer analytical capabilities to the HIM. Secondary electron based imaging can be performed at resolutions down to $0.5 \mathrm{~nm}$ with high contrast, high depth of field and directly on insulating samples. Analytical methods include Secondary Electron Hyperspectral Imaging (SEHI), Scanning Transmission Ion Microscopy (STIM), Backscattering Spectrometry and in particular Secondary Ion Mass Spectrometry (SIMS). The SIMS system that was specifically designed for the HIM allows the detection of all elements, the differentiation between isotopes and the detection of trace elements. It provides mass spectra, depth profiles and 2D or 3D images with lateral resolutions down to $10 \mathrm{~nm}$.
\end{abstract}

\section{Keywords}

Helium Ion Microscopy (HIM), Secondary Ion Mass Spectrometry (SIMS), secondary electrons, highresolution imaging, nano-analytics, correlative microscopy.

\section{Introduction to Helium Ion Microscopy}

The key enabling technology of the Helium Ion Microscope (HIM), which was introduced in 2006, is the so-called Gas Field Ionisation Source (GFIS). This source consists of a sharp needle with an apex radius of about $100 \mathrm{~nm}$ which is biased positively up to $35 \mathrm{kV}$ with respect to the extraction electrode (1). The tip is cryogenically cooled and a He or Ne gas is injected in the vicinity of the tip (Figure 1). The strong electric field around the sharp tip induces field ionisation of the $\mathrm{He}$ or $\mathrm{Ne}$ atoms, which are then accelerated towards the sample. The characteristics of the GFIS include a brightness of $410^{9} \mathrm{~A} /\left(\mathrm{cm}^{2} \mathrm{sr}\right)$, probe sizes smaller than $0.5 \mathrm{~nm}$ and an energy spread of less than $1 \mathrm{eV}(2-5)$. 
The HIM was primarily introduced as an imaging tool, raster scanning the $\mathrm{He}^{+}$ion beam created by the GFIS across the sample and detecting secondary electrons. The HIM progressively became an instrument of choice for ultra-high resolution imaging of both bulk and thinned samples in materials science $(6,7)$ and life science $(8,9)$.

After the GFIS technology became operational with Ne in addition to He (resulting in larger sputter yields and minimised issues with bubble formation), the HIM started to be extensively used for the fabrication of nanoscale structures and deposition applications using a gas injection system (GIS). Applications that have been reported on include the preparation and polishing of TEM lamella (10), the fabrication of plasmonic structures (11), the fabrication of nanopore devices (10), focused $\mathrm{He}^{+}$ ion beam lithography (12), local modification of properties of a material and strain doping $(10,13)$, mask repair (10) and circuit editing (10).

In contrast to Scanning Electron Microscopy (SEM), chemical or elemental information cannot be obtained on the HIM by using X-ray spectroscopy, as the velocity of $30 \mathrm{keV} \mathrm{He}{ }^{+}$or $\mathrm{Ne}^{+}$ions is too small to generate a useful $x$-ray signal from the sample. To overcome this initial lack of analytical information that was seriously hampering a number of applications on the HIM, a lot of efforts have been done by a number of groups in the HIM community during the past several years to develop and test alternative analytical methods on the instrument.

In this paper, we will start by giving an overview on the secondary electron imaging aspects and related applications on the HIM. We will then review the various methodologies and hardware components that have been developed to confer analytical capabilities to the HIM.
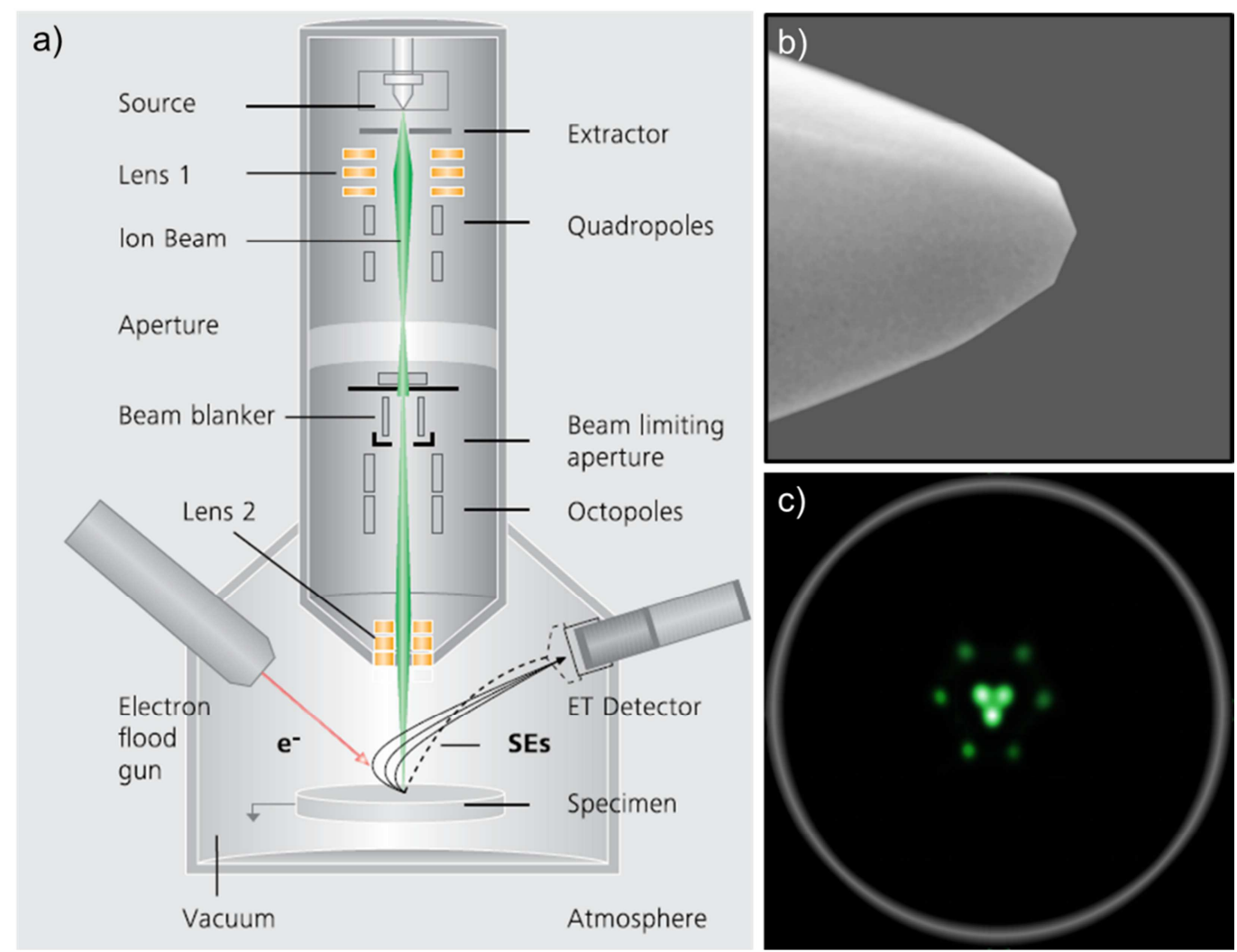

Figure 1: Outline of the ZEISS ORION NanoFab Helium Ion Microscope (a). The emitter with a faceted end-form (b) produces just three beamlets, the "trimer" (c). One atom of the trimer is selected as "the" emitter: the $\mathrm{He}^{+}$or $\mathrm{Ne}^{+}$beam emitted by this atom is selected to travel through the ion optics, while the beams from the other two atoms of the trimer are directed to a beam dump. This use of a 
single atom emitter leads to the observed very high brightness of the GFIS source. Images reproduced with permission by ZEISS.

\section{Overview on imaging on the HIM}

\subsection{Principles}

On the $\mathrm{HIM}, \mathrm{He}^{+}$or $\mathrm{Ne}^{+}$primary ion irradiation leads to an energy transfer to sample electrons, their transport to the sample surface and their emission through the surface barrier when having enough energy. In the latter case they are called secondary electrons (SE). On the HIM, secondary electrons are detected by an Everhart Thornley (ET) detector. SEs can also be emitted by backscattered ions, which are known as SE2. Backscattered ions which interact with the chamber wall can also generate SEs. They are called SE3. In general the SE3 yield is far below the SE1 and SE2 yields and its effect can be lowered by putting a retarding potential on the ET detector (14). The SE yield can be increased when going to higher primary beam energies $(15,16)$. Experimental data has shown that at $20 \mathrm{keV}$ the SE yield of different metals lies in the range of 2 to 8 (17).

Contrast in SE images is created by several mechanisms, including topography, material composition and electrical potentials (18). The SE yield depends on the local angle of incidence of the primary ion beam, leading to some topographic contrast which is present in most HIM images. As the SE2 yield is low on the HIM and SE1s are generated close to the sample surface, the HIM is more surface sensitive than SEM and leads to images with sharper features. The SE yield depends also strongly on the sample composition, producing images with a larger compositional contrast than SEM. Ion channelling produces also contrast under $\mathrm{He}^{+}$or $\mathrm{Ne}^{+}$irradiation. For incidence along low-index planes, ions undergo less hard collisions with the crystalline lattice and produce less SEs. The contrast mechanism depending on electrical potentials is explained by the surface field on insulating samples being reduced by the presence of a buried conducting layer, which leads to a higher SE yield (15). In general, contrast can be enhanced by energy filtering (19).

HIM presents several major advantages as compared to conventional Scanning Electron Microscopy (SEM) (20-22):

- Limitations in probe size that would normally be induced by diffraction can be significantly reduced as the $\mathrm{He}^{+}$and $\mathrm{Ne}^{+}$ions have a substantially shorter effective wavelength than an electron.

- The interaction volume with the sample relative to the escape depth of secondary electrons is considerably smaller under ion irradiation than under electron irradiation. Therefore, the electrons used for imaging are emitted much closer to the beam impact point than on a SEM. In addition the smaller interaction volume and the rareness of large angle scattering events results in the overall SE yield being higher on the HIM than on SEMs (15). These aspects lead altogether to images providing more surface detail.

- Charge compensation is enabled by using an electron flood gun. Therefore, in contrast to SEM, insulating samples can be observed directly without prior deposition of a conductive coating, avoiding nm or sub-nm features being masked (e.g. in biological samples). 
- Highly structured surfaces can be captured with a considerably larger depth of field on the HIM thanks to the 5-10 times smaller convergence angle of the $\mathrm{He}^{+}$or $\mathrm{Ne}^{+}$beam as compared to the electron beam on a SEM.

\subsection{Review of typical applications ranging from materials science to life sciences}

Semiconductor applications represent a major fraction of HIM imaging applications in the field of materials science. The good signal-to-noise ratio and the high depth of field reveal more information than SEM for resist surfaces and sidewalls of photomasks (23). For the localisation of failures in electronic circuits on chips, the charging-up of floating structures in semiconductor circuits under ion irradiation modulates the SE signal intensity and can be used to localise the former. When it comes to image contrast, the Everhart-Thornley detector on HIM performs similar to the SEM with energy selective backscatter detector, showing a linear change of contrast with composition for Gaimplanted Si (24). Although quantification of dopant concentrations is currently highly challenging, lower beam energies and improved detectors may improve the situation (25). Dopant contrast can also be obtained from subsurface features via static capacitive effect (26). 3D-structured semiconductor quantum nanostructures can also be directly resolved by HIM. Pöpsel et al. obtained $\mathrm{nm}$ resolution in superlattices with periods down to $1.5 \mathrm{~nm}$ in core-shell semiconductor nanowires (27). For semiconductor applications, $\mathrm{He}$ and $\mathrm{Ne}$ have the advantage of not contaminating the material by implanting or depositing. Therefore HIM can also be used for the sputtering and characterisation of vias with ultra-high aspect ratio. For this application, the feasibility was demonstrated in a gold film with $5 \mathrm{~nm}$ machining precision achieved (28). The advantage of the electron flood gun for charge compensation is demonstrated for the imaging of cracks in silicon nitride by $\mathrm{He}^{+}$and $\mathrm{Ne}^{+}$ions, where crack edges can be identified in direct imaging by a higher secondary electron yield. However, contrast between different phases is poor. While applying a gold coating was not successful as it completely removed the contrast between phases, the contrast could be slightly improved with a carbon coating (29).

Another application of HIM imaging in materials science is the study of domains in organic solar cell blends. P3HT rich phases have a high SE yield while the yield for PCBM phases is low, which allows to extract information on domain shape and periodicity in the range of 12 to $20 \mathrm{~nm}$ from the images (30).

HIM does not only provide excellent lateral resolution, but is also able to resolve atomic steps on surfaces. They were observed by Hlawacek et al. for Ag deposited on a Pt(111) surface. The different electron work functions of the two materials lead to different SE yields, and hence to intensity contrast which allowed the identification of monatomic steps. The step height was confirmed by Low Energy Electron Microscopy (LEEM) (31).

A detailed review for HIM imaging of carbon nanomembranes can be found in reference (32). For carbon nanomembranes, HIM images reveal much more information than SEM images and a higher contrast between the nanomembranes and substrates. This applies to carbon nanomembranes and to other hybrid and composite 2D systems. Images can show details on film rupture and folding. The 
number of grey levels allows for the calculation of the number of folds for membranes with a thickness of 0.5 to $2 \mathrm{~nm}$ (32).

The high lateral resolution of HIM is also essential for the study of particulate matter in combustion science. Examples include nascent soot and transition metal oxide catalysts (33). For soot particles with a diameter down to $2 \mathrm{~nm}$, HIM allowed for the first time to simultaneously determine size and morphology and to extract the particle size distribution from the projected areas of the particles (34). Depending on the fuel, the structure and aggregation of the particles can change significantly (35). For catalysts, the high depth of field is essential to visualise the surface morphology in order to link it to properties like mechanical strength and catalytic performance, and to study the dependence of morphology and properties on catalyst composition (33). Similar information was obtained for proton exchange membrane fuel cell electrodes where HIM allowed for the study of the morphology of pristine and electrochemically stressed electrodes, to relate morphology features to polymer content and to clarify the electrode structure (36). The properties of nanoporous materials are defined by surface structure, pore shape and pore size. By imaging the surface of a $\mathrm{SiO}_{2}$ catalyst support and performing some automated visualisation and analytics, Burch et al. were able to quantify pore structures (37).

For biological tissues and cells, the major advantage of HIM compared to other techniques is the large depth of field combined with the ability to avoid sample charging by using the electron flood gun. Hence imaging can be done without coating the sample with a conductive metal film which would cover the fine structures on the cell surface or tissue sections (38). The use of the flood gun combined with sub-nm resolution (e.g. maximum magnification of $285 \mathrm{kX}$ ) provides new insights into the ultrastructure of bacteria, single cells and model plants (39). In this context HIM was used to image the epithelium of a rat kidney with high resolution to resolve membrane texture and membraneous nanoprojections on the glomerular podocytes. Compared to SEM, more information could be obtained on pores within the filtration slit diaphragm (40). The use of gold labels to distinguish specific cell-surface proteins was also demonstrated (40). HIM allows also for 3D-like visualisation of the nanoscale fibril morphologies and fibril connections in collagen networks which is important for the research on degeneration and regeneration of articular cartilage collage networks in order to avoid or restore patient disability (8). For cell membranes in mammalian cells, 2D bilayers of amphipathic lipids are organised in transient micro- and nano-domains which are probably involved in the regulation of signal transduction pathways. HIM allowed for the first time for the direct observation of raft-like nano-domains with sizes from 10 to $200 \mathrm{~nm}$ and for fixing their average diameter to $20 \mathrm{~nm}$ (41). For cells exposed to high concentrations of colloidal nanoparticles the disruption of the cellular plasma membrane was observed by HIM (42). The advantage of HIM to resolve the ultrastructure for biological applications can be extended to the characterisation of the glomerulopathy of mice $(43,44)$, and dried cells and epon-embedded tissues (45). Furthermore, HIM imaging can be used to study the initial stages of oligomerisation of peptides (46).

Exact localisation of parasites in cells and their interaction with the host cell can be imaged by HIM. The main advantages of HIM in this field are again the high depth of field and the capability of imaging large areas with high resolution (47). For LLC-MK2 cells infected with Toxoplasma gondii, imaging of the inner part of the cell revealed that parasites present structures which look like secretion, leading to a intravacuolar network with a fine structure and bifurcations (48). The high resolution of HIM was also required to visualise the interaction between bacteria and viruses infecting the former which are called bacteriophages. Imaging at different stages of the infection 
revealed that no bacteria manage to avoid infection and showed how some phages with contracted tails on the bacterial cell were about to inject genome. This process is currently investigated to treat bacterial infections which are difficult to treat with traditional antibiotics (49).

The advantage of SE imaging without the need of metal coating to avoid charging is also observed for the imaging of skin and cuticle of insects. They present many variations to adapt to environmental conditions and HIM can be used to reveal them. This is well illustrated for wild-type and mutant Drosophila melanogaster, where the presence of nanoribbons on bristles depends on the type. The increased depth of field leads to detailed images of the larval midgut and the pulvilli on the Drosophila tarsus (50). For plants, HIM imaging of pine leaves without metal coating revealed the presence and structure of epicuticular wax in the epistomatal chambers and stomata (51).

Performing HIM on butterflies, micro- and nano-structures which are responsible for the colour in butterfly wings could be resolved with high resolution and the photonic band gap could be calculated for the periodic structures underneath the top lamina. By performing stereoscopic imaging consisting in imaging a same region with different tilt angles, the quantitative height information extracted from these images matched the accuracy of cross-sectional TEM measurements but was obtained with much simpler sample preparation. The study was carried out for Papilio ulysses (Blue Mountain Butterfly) and Parides sesostris (Emerald-patched Cattleheart) (52). In general, stereoscopic imaging on the HIM is useful for biological samples with a welldeveloped 3D structure (15).

Similarly, the same advantages of HIM enabled the characterisation of parasitic protozoa and other eukaryotic models, where the micro-tubular sheets of the funis was covered with a lattice-like array material, and small bridges interconnecting the lateral microtubulus of the funis could be visualised (53).

For tooth enamel, analysing at the same time mineral and organic phases with high spatial resolution in three dimensions is a major challenge which has not been solved. Both types of materials can be distinguished on the HIM, the organic phase looking smooth and the mineral crystals seeming to be embedded in the former. Especially for the imaging of very thin crystals of enamel during the early stage of maturation the high resolution and high depth of field of HIM is mandatory. To discern structural details in the organic phase, the larger interaction volume of the electron beam on SEM is required, as HIM is too surface sensitive. Hence, both techniques must be combined to get all information (54). Simultaneous imaging of organic and mineral structures is also important to investigate the time evolution of aggregates formed by Fe(II)-oxidising bacteria which seem to be essential for the elimination of Fe waste from cells (55).

Figure 2 presents typical examples of HIM imaging from the fields of materials science and life sciences. 

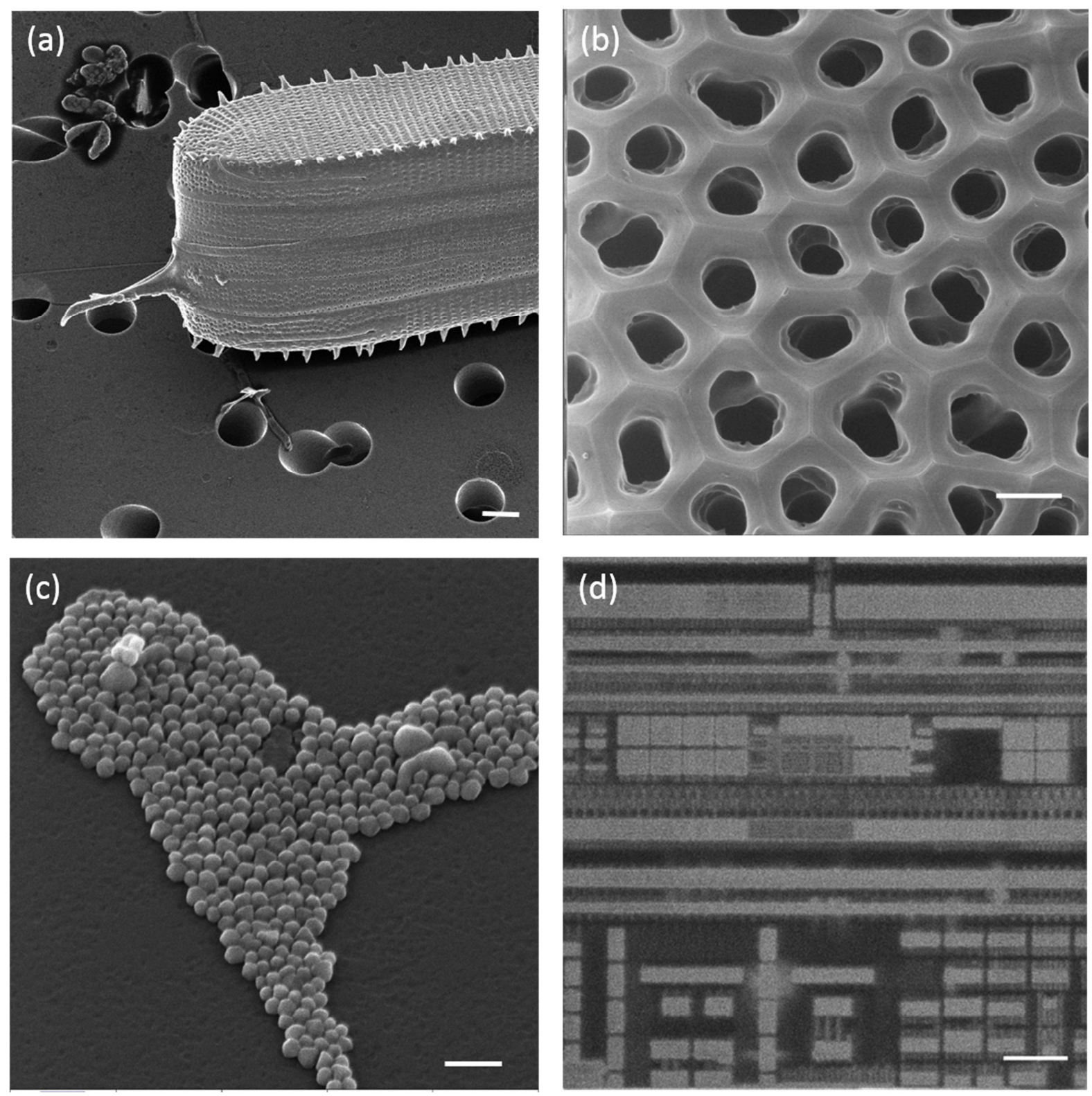

Figure 2: Examples of secondary electron images generated by a $\mathrm{He}^{+}(\mathrm{a}-\mathrm{c})$ and $\mathrm{Ne}^{+}(\mathrm{d})$ ion beam, respectively, highlighting the main capabilities of the HIM: (a) image of a Eunotia rabenhorstian diatom (scale bar: $2 \mu \mathrm{m}$ ) showing the superior depth of field of the HIM as compared to a conventional SEM (56); (b) despite its insulating character, a nanoporous aluminium oxide membrane (scale bar: $250 \mathrm{~nm}$ ) used for filtration and biofunctionalization applications was observed with high lateral resolution and without any metallic coating of the surface; (c) the evaluation of the homogeneity of the dimensions and the shapes of gold nanoparticles (scale bar: $200 \mathrm{~nm}$ ) is enabled by the sub-nanometer resolution of the HIM; (d) investigation of a FinFET (scale bar: $200 \mathrm{~nm}$ ) using the higher sputtering yield of the $\mathrm{Ne}^{+}$ion beam for removal of successive layers as well as for generating secondary electron images of each layer (sample provided by Intel). 


\section{Analytical capabilities on the HIM}

In this section, we will review (in alphabetic order) the various methodologies and hardware components that have been developed to confer analytical capabilities to the HIM.

\subsection{Auger Electron Spectroscopy}

In addition to the emission of secondary electrons, the ion beam irradiation of the sample can also lead to the emission of characteristic Auger electrons from the target atoms as well as from the impinging ions. This process, which is based on the creation of inner-shell holes and their subsequent decay, can be used for so-called ion-induced Auger Electron (IAE) spectroscopy (57). Studies dealing with IAE spectroscopy that have been reported in literature were mainly using noble gas ions with energies ranging from a few keV to a few $100 \mathrm{keV}$ (58-61). More recently Parvaneh and Hull reported on the use of a focused ion beam (FIB) setup (60 keV Si ${ }^{2+}$ and $\left.30 \mathrm{keV} \mathrm{Au}^{+}\right)$to evaluate the IAE spectra of various materials out of the periodic table's third and fourth row $(62,63)$. Based on their results, the authors of these studies are confident that FIB IAE spectroscopy will allow in the future high-sensitivity tomographic imaging containing nano-scale chemical information. To the best knowledge of the authors of the present article no IAE spectroscopy investigations have been done so far on a HIM.

\subsection{Backscattering Spectrometry}

Another kind of particles available within the HIM for analysis purposes are backscattered (BS) He particles. This process relies on the elastic scattering of projectiles with target (sample) particles and is typically done in the MeV range, known as Rutherford Backscattering Spectrometry (RBS). BS in the HIM is done at significantly lower energies $(10-40 \mathrm{keV})$ creating several technical difficulties. These include in particular screening effects influencing the process cross-sections, $\mathrm{dual} / \mathrm{plural} /$ multiple scattering complicating the comparison between simulations and experimental data, sputtering setting a lower size limit for detectable objects and the very small amount of charged BS He needing detectors sensitive to neutrals and ions (64). In order to obtain BS images with elemental contrast an annular Micro Channel Plate (MCP) is often used. Such a set-up allowed for instance the visualisation of heavy nano-particles (such as $\mathrm{Au}$ ) on light substrates (such as $\mathrm{C}$ and $\left.\mathrm{SiO}_{2}\right)(65,66)$. Nevertheless, as the BS yield exhibits an oscillatory trend across the periodic table, using BS contrast does not allow an unambiguous identification of elements $(20,67)$. Therefore, the resulting $B S$ particle energy $\left(E_{B S}\right)$ has to be measured. $E_{B S}$ is dependent on the primary beam energy $E_{\text {prim, }}$, the scattering angle $\Theta$ and the primary/target particle mass ratio $M_{1} / M_{2}$. If $E_{\text {prim }} \Theta$ and $M_{1}$ are known then $M_{2}$ can be determined (10). Using a solid state detector (SDD) located at a fixed $\Theta$ location in the HIM to record $E_{B S}$ spectra, Sijbrandij et al. investigated bulk samples as well as thin films $(67,68)$. Another detection concept is based on Time of Flight (ToF) measurements of the BS He. Different start time options exist, but the most promising setup is the one in which pulsing electronics are used to create $\approx 20$ ns pulses of the primary $\mathrm{He}^{+}$beam (69). In this set-up, an MCP is used as a stop detector of the ToF. By correlating precisely the primary beam scan position on the sample with the recorded BS data it is possible to perform elemental mapping within the HIM. For a proof-of-concept study, Klingner et. al used a carbon-substrate with deposited $\mathrm{Au}, \mathrm{Ni}$ and $\mathrm{Si}$ patches 

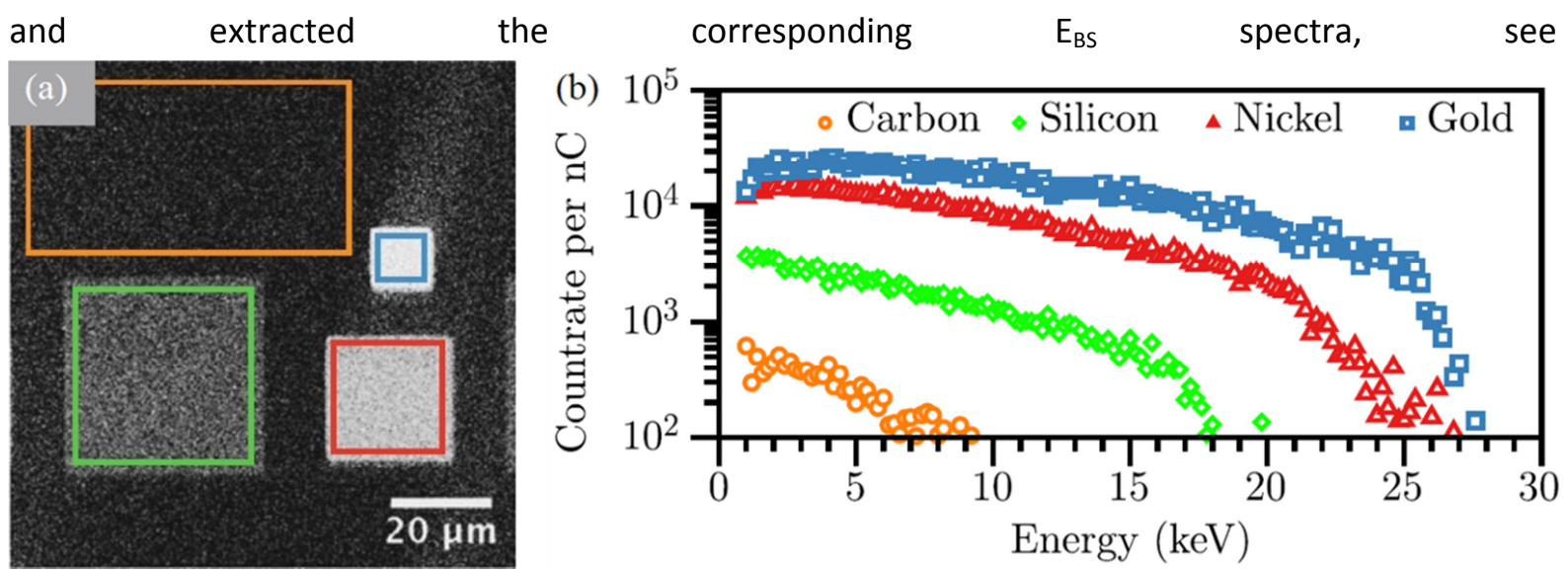

Figure 3. They further measured on the Ni patch an edge resolution of $\approx 54 \mathrm{~nm}(69)$. In general the BS yield is quite low $\left(10^{-3}\right.$ to $\left.10^{-1}(67)\right)$ and the detectors only cover a small portion of solid angle above the surface so that care must be taken to create highly sensitive BS detectors. Furthermore, very often experimental results need to be compared with simulations for precise elemental identification which can result in time consuming data analysis.
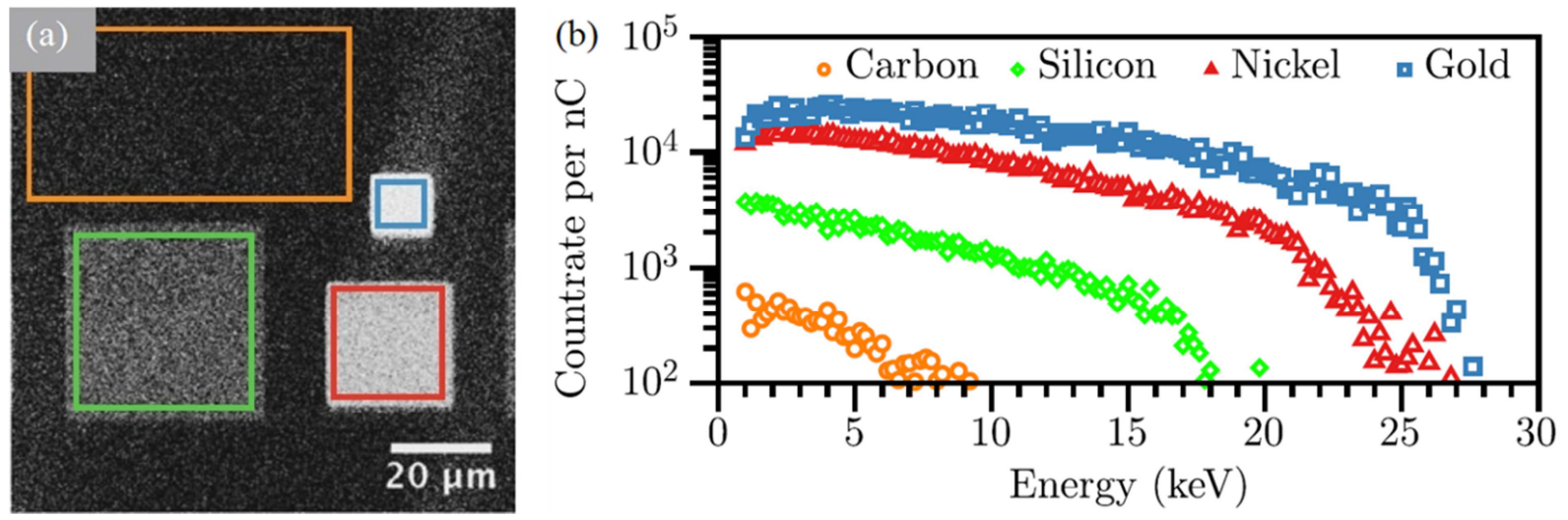

Figure 3: a) ToF-BS mode image: glassy carbon substrate (orange), Si-patch (green), Ni-patch (red), Au-patch blue; b) BS He energy spectra of the different sample regions. Reprinted from (69) with permission from Elsevier.

\subsection{Channeling}

When imaging crystalline samples on the HIM the mechanism of channeling plays an important role. If the orientation of the He beam with respect to the crystal lattice is close to a low index direction, the beam channels into the crystal structure without undergoing hard collisions resulting in a decrease of the SE/BS yield. If different crystalline regions are present within a sample it is possible to observe channeling contrast so that HIM channeling imaging can lead to analogous results than Electron Back Scatter Diffraction (EBSD) performed on a SEM (70). As a proof of concept, Veligura et al mapped the grain orientation within a polycrystalline gold sample (71). It has been shown that channeling can be blocked or reduced by depositing adlayers on crystalline substrates or by having local lattice distortions (70). Note that for all the HIM channeling studies reported here a ultra-high vacuum microscope configuration was used to minimise the effect of unwanted hydrocarbon surface layers on the channeling mechanism $(31,70,71)$. 


\subsection{Ionoluminescence}

The interaction of the impinging $\mathrm{He}^{+}$ion beam with the sample may result in photon emission caused by transitions in the electronic system. This process is called ionoluminescence (IL). Even though the IL emission can also originate from BS He atoms or sputtered particles the main signal in the HIM originates from the sample as the BS and sputter yields are low. IL can be split into two main types: extrinsic, related to impurities (activators), and intrinsic, linked to free electron recombinations within the sample material (72). He induced IL studies (imaging and spectral measurements) on the HIM have been reported for various kinds of samples, e. g. semi-conductors (bulk and nanowires) (73-75), $\mathrm{SiO}_{2}(76)$, alkali-halides (77), sapphire (78), fluorites such as $\mathrm{CaF}_{2}(72)$ and biological samples using immunofluorescene (IF) $(73,74)$. These studies revealed that the detected IL signal is quite low and that it quickly becomes unstable with irradiation dose, in particular due to defect formation induced by the ion irradiation, limiting the use of IL for analytical purposes in practice.

\subsection{Scanning Transmission Ion Microscopy}

While ion transmission investigations are typically carried out using $\mathrm{MeV}$ ion energies $(79,80)$, recently Scanning Transmission Ion Microscopy (STIM) studies using sub-50 $\mathrm{keV} \mathrm{He}^{+}$ions have been reported. The simplest setup for STIM consists in positioning a thin sample above a surface coated with a high SEY material used to convert the transmitted He particles into a SE signal which is detected with the HIM's standard SE detector. Such a setup was used in studies dealing with thickness determinations of free standing SiN membranes (81), characterisation of nano-vias in gold films (28) and nanopore fabrication in SiN, carbon nanomembranes or graphene (82). A more sophisticated approach for STIM that was introduced more recently consists in positioning a transmission detector directly underneath the thin sample $(83,84)$. STIM is expected to allow imaging with atomic resolution (de Broglie wavelength of $30 \mathrm{keV} \mathrm{He}^{+}$is only $83 \mathrm{fm}$ ) and modes as Bright Field (BF) imaging, giving mass density variation contrast, or Dark Field (DF) imaging, giving atomic number contrast, can be used $(18,85)$. Also ion channeling can play a role as contrast mechanism in STIM imaging (86). Furthermore, ion diffraction patterns can be investigated as shown in (85) for MgO crystals. A clear advantage of STIM is that sub-surface features can be probed without the need of damaging the sample as bulk information is accessible. For example nanoparticles contained within biological tissues could be imaged. A further operation mode with sub-50 $\mathrm{keV} \mathrm{He}^{+}$STIM is Ion Energy-Loss Spectroscopy (IELS) which so far is relatively underexplored, but which could provide unique quantitative insights on ion-solid interactions.

\subsection{Secondary Electron Hyperspectral Imaging}

A comparison of the SE energy spectra from different material phases within a sample allows to determine energy thresholds and windows, which can then be applied during SE imaging to separate the different phases. This procedure is referred to as SE hyperspectral imaging $(\mathrm{SEHI})(87,88)$ and can allow the exploration of chemical variations in the sample. It has furthermore the advantage of maximising the image contrast while reducing the beam exposure time which is of importance for beam sensitive samples (87). Currently, the recording of SE spectra on the HIM can be performed by scanning the voltage difference between the sample and the detector surrounding grid. To shorten the acquisition time and hence to reduce the beam exposure time, but also to increase the detection 
efficiency, parallel electron energy analysers such as proposed by Khursheed (89) would need to be implemented.

\subsection{Secondary Ion Mass Spectrometry}

The impinging $\mathrm{He}^{+}$or $\mathrm{Ne}^{+}$ions penetrate into the sample and lose their energy progressively during collisions with target atoms. These collision cascades lead to sputtering of target atoms and molecules, but also to recoil and cascade mixing, implantation of the projectile and radiation induced diffusion. Some of the target atoms or molecules are spontaneously ionised during the sputtering process. These so-called secondary ions can be collected by an electric field and injected into a mass spectrometer to perform Secondary lon Mass Spectrometry (SIMS). SIMS is an extremely powerful technique for analysing surfaces owing in particular to its excellent sensitivity (detection limits down to the ppb are possible, so that SIMS can be used to detect both major and trace elements), high dynamic range (a same signal can be followed over several orders of magnitude), very high mass resolution and its ability to differentiate between isotopes. The possibility of performing SIMS on the HIM using $\mathrm{He}^{+}$and $\mathrm{Ne}^{+}$primary ion beams was first investigated by Wirtz et al. (90).

The secondary ion signal detected for a given element $\mathrm{M}$ can be written as $I_{M}=I_{p} \cdot Y \cdot C_{M} \cdot \beta_{M} \cdot \tau$, where $I_{p}$ is the primary ion current hitting the analysed area, $Y$ is the sputtering yield, $C_{M}$ is the concentration of species $\mathrm{M}, \beta_{M}$ is the ionisation probability of that element and $\tau$ is the transmission of the mass spectrometer and the detection efficiency. Experimental studies and simulations show that the sputter yields obtained for $\mathrm{Ne}$ are on average one order of magnitude higher than those obtained for $\mathrm{He}$ and only slightly lower than those obtained with primary ion species that are conventionally used in SIMS (91). The ionisation probability $\beta_{M}$ strongly depends on the nature and composition of the sample and the nature of the impinging ions. As a result of this phenomenon, which is referred to as the matrix effect, the detected SIMS signals are not directly quantitative, and well-defined protocols, mostly based on reference samples, need to be applied to convert the secondary ion signal detected for a given element to the concentration of that same element in the analysed sample (92). In order to maximise $\beta_{M}$ and hence the detected secondary ion signal, reactive primary ion species are typically used in SIMS (cesium and oxygen primary ion species to enhance the emission of negative and positive secondary ions, respectively). Alternatively, or in addition, the sample surface can be exposed to a flux of reactive gas during $\operatorname{SIMS}$ analysis $\left(\mathrm{O}_{2}\right.$ for optimising the emission of positive secondary ions (93), Cs for negative secondary ions (94-97)). Such a use of reactive gas flooding is of particular interest in the case of the HIM as sputtering is performed with non-reactive $\mathrm{He}^{+}$or $\mathrm{Ne}^{+}$primary ions (91).

A dedicated SIMS instrument was developed for the HIM by Wirtz and Dowsett and introduced to the community in 2015 (Figure 4) (98-101). This SIMS add-on system consists of extraction optics allowing a maximised secondary ion collection efficiency while minimising artefacts regarding the primary ion beam focussing, a compact high-performance double focusing magnetic sector mass spectrometer and an integrated reactive gas flooding system that can deliver $\mathrm{O}_{2}$ and $\mathrm{Cs}$ gas onto the analysed area for the enhancement of positive and negative secondary ions, respectively (101). A double focussing magnetic sector mass spectrometer was chosen over other spectrometer types that are also used in SIMS instrumentation (such as quadrupole or time-of-flight systems) because of its significant advantages in this particular configuration. In this spectrometer, achromatic mass filtering (i.e. independent of the initial energy distribution of the secondary ions) is achieved by 
combining an electrostatic analyser with the magnetic filter. As a Mattauch-Herzog design is used, all masses are focussed in a same focal plane so that parallel detection of several masses (or even all masses with an appropriate detector) is possible. More details and technical specifications about the magnetic sector SIMS system for the HIM can be found in (101).

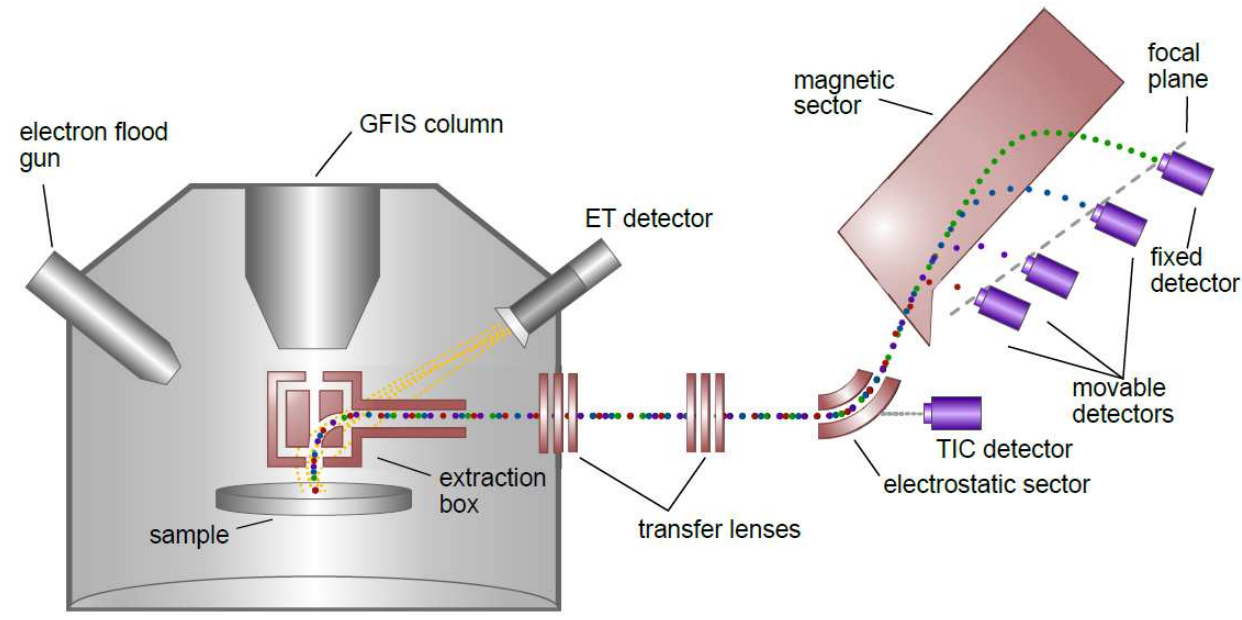

Figure 4: Schematics of the double focussing magnetic sector SIMS system for the HIM.

SIMS analyses on the HIM can be performed in the three typical analysis modes, i.e. acquisition of mass spectra (Figure 5), depth profiling and imaging (Figure 6).

The generation of mass spectra in view of determining the surface composition of the analysed sample is the most basic application of SIMS. In contrast to EDS spectra obtained on a SEM, the SIMS mass spectra obtained on the HIM allow the detection of all elements (including the very light ones), the differentiation between isotopes and better detection limits. As an example, Figure 5 shows a mass spectrum obtained with the magnetic sector SIMS on a Copper Indium Gallium Selenide (CIGS) solar cell. This mass spectrum has a mass resolution $\mathrm{M} / \Delta \mathrm{M}$ of 550 and shows the different isotopes of $\mathrm{Cu}, \mathrm{Ga}, \mathrm{Se}, \mathrm{Rb}$ and In. SIMS mass spectra were also recorded by Klingner et al. using the ToF system developed for backscattering measurements that is presented in section 3.5 (69). In this work, the mass resolution $\mathrm{M} / \Delta \mathrm{M}$ was limited to $\sim 12$ as, in contrast to the double focussing magnetic sector SIMS, the ToF system used for these measurements did not allow for achromatic filtering and as quite long primary ion beam pulses were used to avoid a deterioration of the spot size and hence of the spatial resolution (69). 


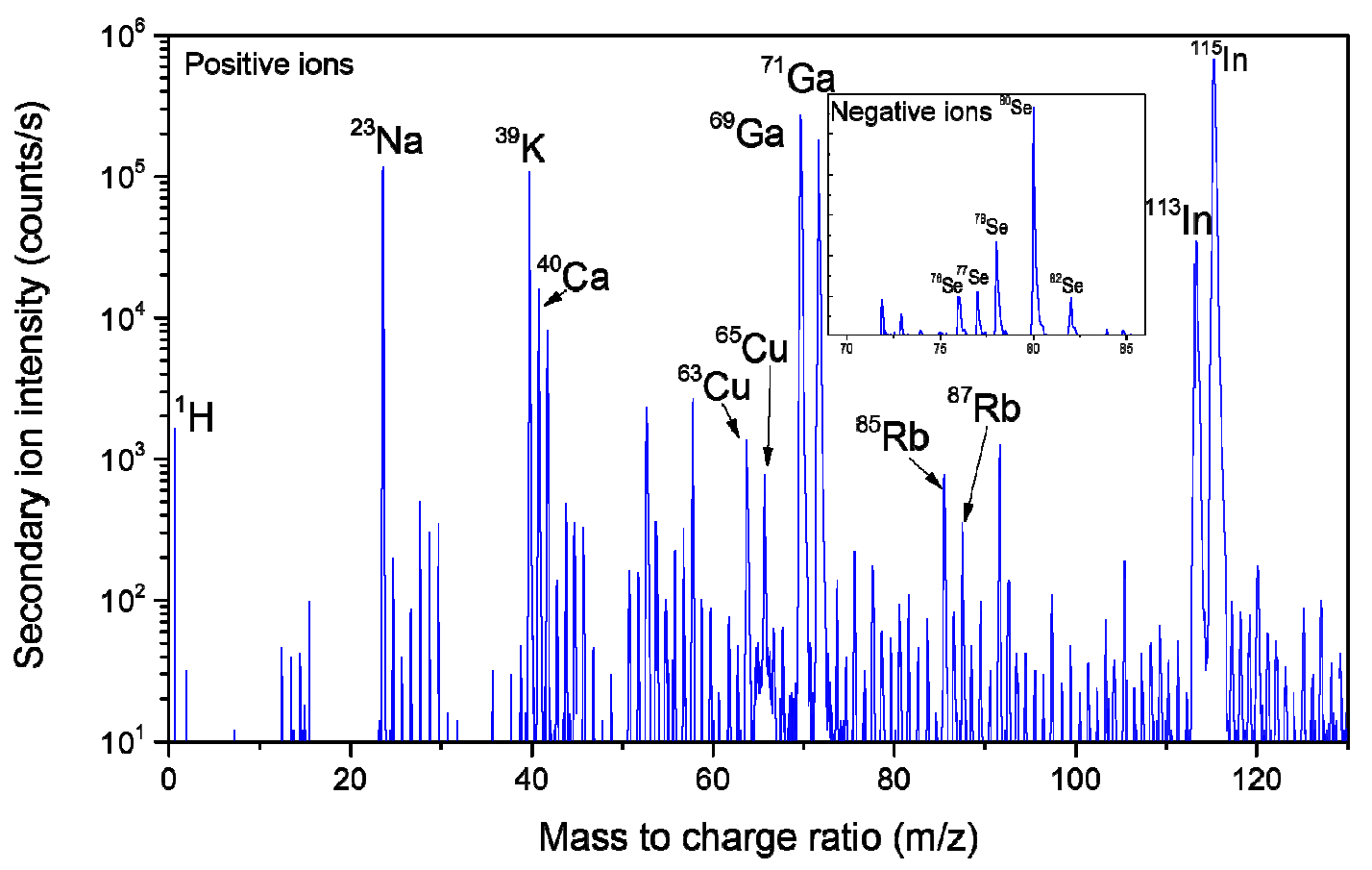

Figure 5: Secondary ion mass spectrum obtained with the magnetic sector SIMS system of the absorber layer of a Copper Indium Gallium Selenide (CIGS) solar cell after applying a rubidium fluoride (RbF) post deposition treatment. The sample was sputtered by a $20 \mathrm{keV} \mathrm{Ne}{ }^{+}$beam at a primary ion current of $20 \mathrm{pA}$. While the positive secondary ion mass spectrum shows the peaks of most of the elements of interest, including their isotopes, the Se isotopes are best detected in the negative secondary ion polarity (insert).

SIMS depth profiling consists in progressively eroding the sample with the ion beam and recording selected secondary ion signals with respect to time, which is then converted into a depth scale after calibration (typically calibrating the erosion rates by using reference samples or by performing postanalysis crater measurements by profilometry). Using $\mathrm{Ne}^{+}$irradiation in the low keV range, depth resolutions in the 10 to $20 \mathrm{~nm}$ range can be achieved. For higher energies and $\mathrm{He}^{+}$irradiation the atomic mixing becomes in general too important to distinguish $\mathrm{nm}$ sized features in the z-direction (102). Another important aspect which needs to be taken into account under light ion irradiation is preferential sputtering which leads to a substantial change in surface concentrations (103).

SIMS depth profiling on the HIM can be performed on extremely small zones of a few hundred nanometres or less, which is a unique advantage for semiconductor end-pointing applications and process control during nano-machining. As a proof of concept example, a $\mathrm{SiCOH} / \mathrm{Cu} / \mathrm{Si}$ test structure was depth profiled (98). The depth profile of the Cu signal showed a sharp rising edge, allowing for a precise localisation of the $\mathrm{SiCOH} / \mathrm{Cu}$ interface and hence for an unambiguous definition of the blanking of the primary ion beam in an end-pointing application. Unlike using contrast variations in the SE signal for end-pointing, SIMS depth profiles provide a binary information (in the case of the mentioned example the $\mathrm{Cu}$ signal rises from 0 counts/s to 100 counts/s when reaching the $\mathrm{SiCOH} / \mathrm{Cu}$ interface) and are hence a much more precise indicator.

SIMS imaging with the magnetic sector SIMS instrument on the HIM is performed in the so-called microprobe mode. The field of view on the sample is raster-scanned with the $\mathrm{He}^{+}$or $\mathrm{Ne}^{+}$beam and 
the detection of the secondary ions is synchronised with the scan signal to reconstruct the mass filtered images pixel by pixel. While the imaging resolution in the microprobe mode is essentially determined by the spot size of the primary ion beam on conventional SIMS instruments, the achievable spot sizes on the HIM are so small that the SIMS resolution is only limited by the dimensions of the collision cascade triggered by the $\mathrm{He}^{+}$or $\mathrm{Ne}^{+}$impacts. Therefore, magnetic sector SIMS imaging on the HIM leads to unprecedented levels of performance with $10 \mathrm{~nm}$ resolution demonstrated e.g. by Dowsett et al. (as compared to $50 \mathrm{~nm}$ on the Cameca NanoSIMS50 instrument) (101). The magnetic sector SIMS on the HIM was used for a number of imaging applications, including the investigation of various types of photovoltaic and optoelectronic devices $(100,104$, 105) (Figure 6), battery research, investigation of FinFETs, imaging of human chromatine in single cells, diffusion studies in biomedical devices, identification of nanoparticles in complex products (e.g. cosmetics) (106), etc. SIMS imaging was also tested with the ToF system designed for backscattering measurements, but the duty cycle introduced by pulsing the primary ion beam leads to a number of disadvantages in terms of sensitivity and/or analysis duration. The ToF approach either leads to very significantly increased acquisition times $(x 100)$ as compared to the magnetic sector which can operate in the DC mode or, for a same acquisition time, intrinsically limits the sensitivity (99).

The availability of both SIMS imaging and SE imaging capabilities on the same instrument enables unique in-situ correlative imaging combining elemental/chemical information obtained by SIMS with high resolution $(0.5 \mathrm{~nm})$ secondary electron images of the same zone (see example in Figure 6). The treatment of the correlative SIMS and SE images can range from simple co-registration (101) to sophisticated image fusion algorithms (107). Examples of applications for correlative SIMS-SE imaging on the HIM include the identification of LTO and $\mathrm{MgO}$ nanoparticles within a nanoparticle mixture (101), the localisation of $\mathrm{Br}$ and I enriched areas in mixed cation/mixed halide perovskite solar cells (100), the identification of Cs enriched grains in organic-inorganic halide perovskites (104), the determination of the distribution of alkali elements with respect to the grain boundaries in CIGS solar cells (Figure 6) and the nano-scale investigation of Li ion batteries.

Finally, 3D SIMS volume reconstructions can be generated by acquiring a series of 2D image frames and putting them into a 3D image stack. The conversion from frame number to depth is carried out applying protocols similar to the ones mentioned earlier for depth profiling. To avoid artefacts occurring under traditional 3D SIMS image stacking (108-110), Vollnhals et al. developed a methodology consisting in combining SIMS data with a photogrammetric topography reconstruction obtained by acquiring SE images at different angles on the HIM (111). 

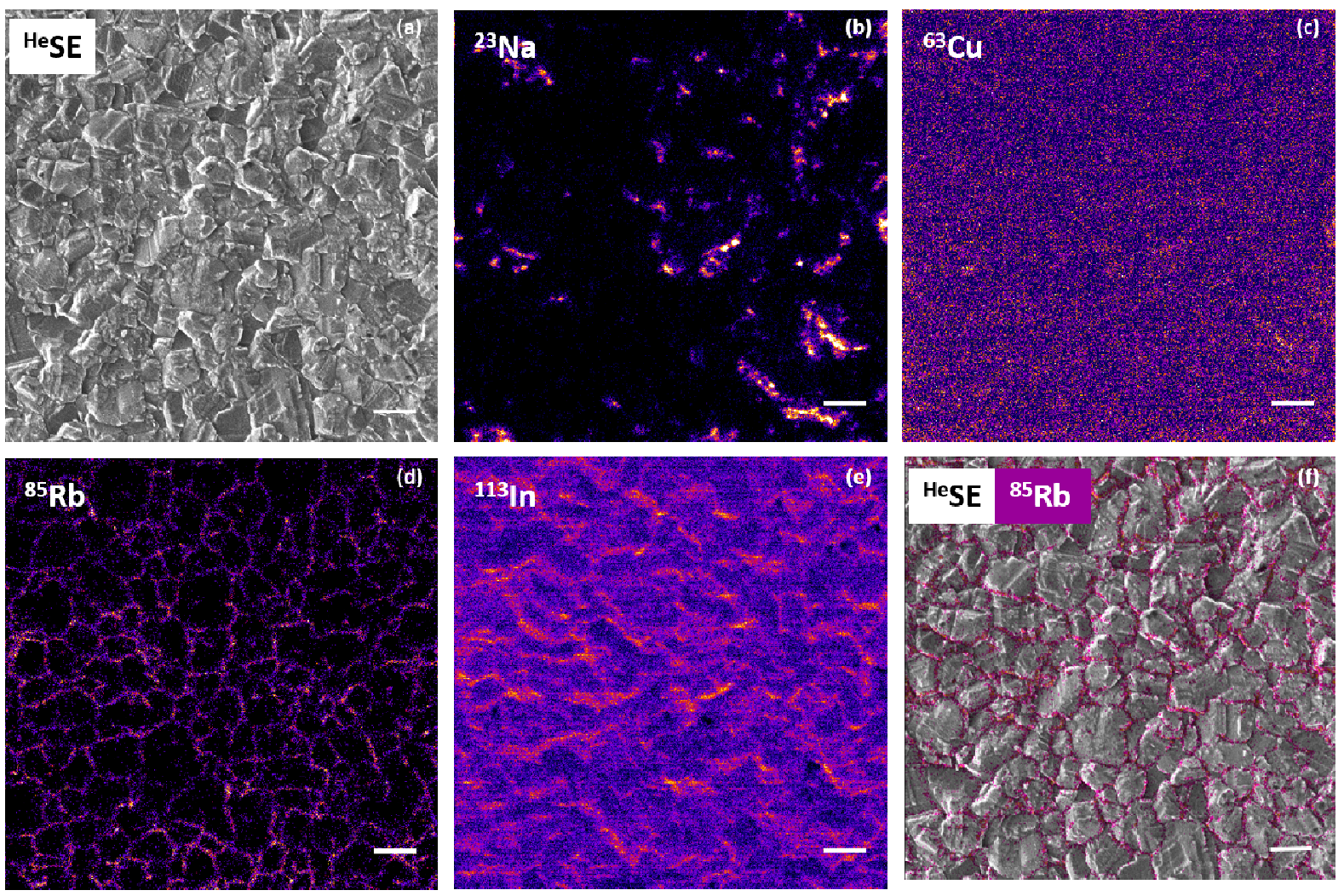

Figure 6: Magnetic sector SIMS imaging and correlative analysis of a Copper Indium Gallium Selenide (CIGS) solar cell after applying a rubidium fluoride (RbF) post deposition treatment. (a) Secondary electron image (1024x1024 pixels) obtained with a $\mathrm{He}^{+}$beam (20keV, $\left.1 \mathrm{pA}\right)$. (b)-(e) SIMS images (512x512 pixels, dwell time per pixel of $5 \mathrm{~ms}$ ) generated with a $\mathrm{Ne}^{+}$beam $(20 \mathrm{keV}, 3 \mathrm{pA})$. The masses that are displayed are Sodium (b), Copper (c), Rubidium (d) and Indium (e). (f) Co-registered SE and ${ }^{85} \mathrm{Rb}$ images showing that the Rubidium is accumulated along the grain boundaries. Scale bar: $2 \mu \mathrm{m}$.

\subsection{X-Ray Spectroscopy}

In contrast to SEM, chemical or elemental information cannot be obtained on the HIM by using X-ray spectroscopy, as the velocity of $30 \mathrm{keV} \mathrm{He}^{+}$or $\mathrm{Ne}^{+}$ions is too small to generate useful $\mathrm{x}$-ray signals from the sample. Experiments performed by S. Sijbrandij with a $29.5 \mathrm{keV} \mathrm{He}^{+}$beam on a $\mathrm{Cu}$ sample lead to a Cu-peak containing only around 50 counts after 12.5 hours of irradiation at an ion current of $375 \mathrm{pA}$. The X-Ray generation rate that can be deduced from this experimental measurements using basic geometrical considerations is on the order of $10^{-10}$ per incident ion and hence of the same order of magnitude as the values reported by Giannuzzi and Gorman for $\mathrm{Ga}^{+}$ion irradiation (112). This yield obtained with a $29.5 \mathrm{keV} \mathrm{He}^{+}$beam is up to 7 orders of magnitude lower than the yields obtained with an electron beam at the same energy (113).

\section{Conclusions}

The Helium Ion Microscope (HIM) has emerged as an instrument of choice for patterning, imaging and more recently analytics at the nano-scale.

While the instrument's $\mathrm{Ne}^{+}$ion beam allows structures with sub $20 \mathrm{~nm}$ feature sizes to be patterned, the $\mathrm{He}^{+}$ion beam allows even smaller sizes to be achieved. 
Secondary electron (SE) based imaging can be performed on the HIM with resolutions down to 0.5 and $2 \mathrm{~nm}$ when scanning the sample with $\mathrm{He}^{+}$and $\mathrm{Ne}^{+}$beams, respectively. The combination between probing the sample with light ions and detecting emitted electrons confers unique capabilities to the HIM, including high contrast imaging, high depth of field and direct imaging of insulating samples. Typical fields of application in materials science include semiconductors, nanomembranes and two-dimensional materials, catalysts, solar cells and fuel cells. In the field of life sciences, HIM imaging was for instance successfully used to image tissues at the cellular level, organs, plants, wings of butterflies and teeth.

As chemical or elemental information cannot be obtained on the HIM by using X-ray spectroscopy, various alternative analytical methods along with appropriate instrumentation have been developed, optimised and applied to a number of fields in materials science, life sciences and beyond. Among these analytical methods, Secondary lon Mass Spectrometry (SIMS) is standing out. The magnetic sector SIMS system that was specifically designed for the HIM allows the detection of all elements (including the very light ones), the differentiation between isotopes and the detection of trace elements thanks to its sensitivity. The SIMS can be run in the mass spectrum acquisition mode, the depth profiling mode and the 2D or 3D imaging mode. In the imaging mode, the SIMS is capable of producing elemental maps with lateral resolutions down to $10 \mathrm{~nm}$. Furthermore, HIMSIMS opens the way for in-situ correlative imaging combining high resolution SE images with elemental and isotopic ratio maps from SIMS. This approach allows SIMS images of exactly the same zone mapped in the SE mode to be acquired easily and rapidly, followed by a fusion between the SE and SIMS data sets.

Very interesting prospects are also offered by Secondary Electron Hyperspectral Imaging (SEHI) and Scanning Transmission Ion Microscopy (STIM), but these techniques will only be able to be exploited at their full potential after appropriate instrumentation (parallel energy analyser for the former, high-resolution position sensitive detector for the latter) become available. While SEHI is based on using specific energy thresholds and windows to explore chemical variations in the sample, STIM can enable Ion Energy-Loss Spectroscopy (IELS) on top of Bright Field and Dark Field imaging. Auger Electron Spectroscopy might also have a very interesting potential, but it has not been tested with $\mathrm{He}^{+}$or $\mathrm{Ne}^{+}$ions yet.

The list of analytical techniques on the HIM furthermore includes Backscattering Spectrometry that can provide some compositional information but without allowing unambiguous identification of elements, channeling measurements allowing the determination of crystal orientations and ionoluminescence based on photon detection to collect information about the sample under investigation.

\section{Acknowledgements}

The authors thank John Notte and Sybren Sijbrandij from ZEISS for the very helpful discussions, in particular regarding X-Ray Spectroscopy experiments on the HIM.

This project has received funding from the European Union's Horizon 2020 research and innovation programme under grant agreement No 720964 . This work was also co-funded by the National Research Fund Luxembourg (FNR) within the framework of the HELION project through grant 
C14/MS/8345352, the STHIM project through grant C16/MS/11354626 and the SOLAR4D project through grant INTER/SNF/16/11534230. 


\section{References}

1. Ward BW, Notte JA, Economou NP. 2006. Helium ion microscope: A new tool for nanoscale microscopy and metrology. J. Vac. Sci. Technol. B. 24(6):2871

2. Hill R, Notte J, Ward B. 2008. The ALIS He ion source and its application to high resolution microscopy. Phys. Procedia. 1(1):135-41

3. Scipioni L, Stern LA, Notte J, Sijbrandij S, Griffin B. 2008. Helium ion microscope. Adv. Mater. Process. 166(6):27-30

4. Notte J, Hill R, McVey S, Farkas L, Percival R, Ward B. 2006. An Introduction to Helium Ion Microscopy. Microsc. Microanal. 12(S02):126-27

5. Rahman FHM, McVey S, Farkas L, Notte JA, Tan S, Livengood RH. 2012. The Prospects of a Subnanometer Focused Neon lon Beam. Scanning. 34(2):129-34

6. Fox D, Zhou YB, O'Neill A, Kumar S, Wang JJ, et al. 2013. Helium ion microscopy of graphene: beam damage, image quality and edge contrast. Nanotechnology. 24:335702

7. Bazargan S, Heinig NF, Rios JF, Leung KT. Electronic Transport in Tin(IV) Oxide Nanocrystalline Films: Two-Medium Transport with Three-Dimensional Variable-Range Hopping Mechanism for the Ultrasmall Nanocrystallite Size Regime. J. Phys. Chem. C. 116(8):4979-85

8. VANDEN BERG-FOELS WSS, SCIPIONI L, Huynh C, Wen X. 2012. Helium ion microscopy for high-resolution visualization of the articular cartilage collagen network. J. Microsc. 246(2):168-76

9. Chen X, Udalagama CNB, Chen CB, Bettiol AA, Pickard DS, et al. 2011. Whole-Cell Imaging at Nanometer Resolutions Using Fast and Slow Focused Helium lons. Biophys. J. 101(7):1788-93

10. Hlawacek G, Gölzhäuser A, eds. 2016. Helium Ion Microscopy. Springer International Publishing Switzerland. p.

11. Melli M, Polyakov A, Gargas D, Huynh C, Scipioni L, et al. 2013. Reaching the Theoretical Resonance Quality Factor Limit in Coaxial Plasmonic Nanoresonators Fabricated by Helium Ion Lithography. Nano Lett. 13(6):2687-91

12. Sidorkin V, van Veldhoven E, van der Drift E, Alkemade P, Salemink H, Maas D. 2009. Sub-10$\mathrm{nm}$ nanolithography with a scanning helium beam. J. Vac. Sci. Technol. B Microelectron. Nanom. Struct. 27(4):L18

13. Belianinov A, Iberi V, Tselev A, Susner MA, McGuire MA, et al. 2016. Polarization Control via He-Ion Beam Induced Nanofabrication in Layered Ferroelectric Semiconductors. ACS Appl. Mater. Interfaces. 8(11):7349-55

14. Petrov Y V., Vyvenko OF. 2016. Secondary Electron Generation in the Helium Ion Microscope: Basics and Imaging. In Helium Ion Microscopy, ed G Hlawacek, A Gölzhäuser, pp. 119-46. Springer, Cham. NanoScienc ed.

15. Boden SA. 2016. Introduction to Imaging Techniques in the HIM. In Helium Ion Microscopy, ed G Hlawacek, A Gölzhäuser, pp. 149-72. Springer, Cham. NanoScienc ed.

16. Ramachandra R, Griffin B, Joy D. 2009. A model of secondary electron imaging in the helium ion scanning microscope. Ultramicroscopy. 109(6):748-57

17. Morgan J, Notte J, Hill R, Ward B. 2006. An introduction to the Helium Ion Microscope. Micros. Today. 24(S02):126-27 
18. Scipioni L, Sanford CA, Notte J, Thompson B, Mcvey S. 2009. Understanding imaging modes in the helium ion microscope

19. Mikhailovskii VY, Petrov Y V, Vyvenko OF. 2015. Energy filtration of secondary and backscattered electrons by the method of the retarding potential in scanning electron and ion microscopy. J. Surf. Investig. X-ray, Synchrotron Neutron Tech. 9:196-202

20. Hlawacek G, V.Veligura, Gastel R, Poelsema B. 2014. Helium ion microscopy. J. Vac. Sci. Technol. B. 32:1-13

21. Joy D. 2013. Helium Ion Microscopy: Principles and Applications. Springer. 1-64 pp.

22. Maas DJ, Van Gastel R. 2013. Helium Ion Microscopy. In Surface Science Techniques, ed G Bracco, B Holst, pp. 461-97. Springer

23. Livengood R, Tan S, Greenzweig Y, Notte J, McVey S. 2009. Subsurface damage from helium ions as a function of dose, beam energy, and dose rate. J. Vac. Sci. Technol. B Microelectron. Nanom. Struct. 27(6):3244-49

24. O'CONNELL R, CHEN Y, ZHANG H, ZHOU Y, FOX D, et al. 2017. Comparative study of image contrast in scanning electron microscope and helium ion microscope. J. Microsc. 268(3):31320

25. Chee AKW, Boden SA. 2016. Dopant profiling based on scanning electron and helium ion microscopy. Ultramicroscopy. 161:51-58

26. Jepson MAE, Inkson BJ, Liu X, Scipioni L, Rodenburg C. 2009. Quantitative dopant contrast in the helium ion microscope. Epl. 86(2):

27. Pöpsel C, Becker J, Jeon N, Döblinger M, Stettner T, et al. 2018. He-lon Microscopy as a HighResolution Probe for Complex Quantum Heterostructures in Core-Shell Nanowires. Nano Lett. 18(6):3911-19

28. Scipioni L, Ferranti DC, Smentkowski VS, Potyrailo RA. 2010. Fabrication and initial characterization of ultrahigh aspect ratio vias in gold using the helium ion microscope. J. Vac. Sci. Technol. B, Nanotechnol. Microelectron. Mater. Process. Meas. Phenom. 28(6):C6P18C6P23

29. Baggott A, Mazaheri M, Zhou Y, Zhang H, Inkson BJ. 2018. A comparison of He and Ne FIB imaging of cracks in microindented silicon nitride. Mater. Charact. 141:362-69

30. Pearson AJ, Boden SA, Bagnall DM, Lidzey DG, Rodenburg C. 2011. Imaging the Bulk Nanoscale Morphology of Organic Solar Cell Blends Using Helium Ion Microscopy. Nano Lett. 11:4275-81

31. Hlawacek G, Jankowski M, Wormeester H, van Gastel R, Zandvliet HJW, Poelsema B. 2016. Visualization of steps and surface reconstructions in Helium Ion Microscopy with atomic precision. Ultra. 162:17-24

32. Gölzhäuser A. 2016. Helium Ion Microscopy of Carbon Nanomembranes. In Helium Ion Microscopy, ed G Hlawacek, A Gölzhäuser, pp. 225-44. Springer, Cham. NanoScienc ed.

33. Vieker H, Beyer A. 2016. HIM Applications in Combustion Science: Imaging of Catalyst Surfaces and Nascent Soot. In Helium Ion Microscopy, ed G Hlawacek, A Gölzhäuser, pp. 187203. Springer, Cham. NanoScienc ed.

34. Schenk M, Lieb S, Vieker H, Beyer A, Gölzhäuser A, et al. 2013. Imaging Nanocarbon 
Materials: Soot Particles in Flames are Not Structurally Homogeneous. ChemPhysChem. 14(14):3248-54

35. Schenk M, Hansen H, Vieker H, Beyer A, Gölzhäuser A, Kohse-Höinghaus K. 2015. PAH formation and soot morphology in flames of C4 fuels. Proc. Combust. Inst. 35:1761-69

36. Chiriaev S, Dam Madsen N, Rubahn H-G, Ma Andersen S. 2017. Helium Ion Microscopy of proton exchange membrane fuel cell electrode structures. AIMS Mater. Sci. 4(6):1289-1304

37. Burch MJ, levlev A V, Mahady K, Hysmith H, Rack PD, et al. 2018. Helium Ion Microscopy for Imaging and Quantifying Porosity at the Nanoscale. Anal. Chem. 90(2):1370-75

38. Gölzhäuser A, Hlawacek G. 2016. HIM of Biological Samples. In Helium Ion Microscopy, ed G Hlawacek, A Gölzhäuser, pp. 173-85. Springer, Cham. NanoScienc ed.

39. Joens MS, Huynh C, Kasuboski JM, Ferranti D, Sigal YJ, et al. 2013. Helium Ion Microscopy (HIM) for the imaging of biological samples at sub-nanometer resolution. Sci. Rep. 3:3514

40. Rice WL, Hoek AN Van, Pa TG, Unescu ", Huynh C, et al. 2013. High Resolution Helium Ion Scanning Microscopy of the Rat Kidney. PLoS One

41. Schürmann M, Frese N, Beyer A, Heimann P, Widera D, et al. 2015. Helium Ion Microscopy Visualizes Lipid Nanodomains in Mammalian Cells. Small. 11(43):5781-89

42. Ma X, Hartmann R, Jimenez de Aberasturi D, Yang F, Soenen SJH, et al. 2017. Colloidal Gold Nanoparticles Induce Changes in Cellular and Subcellular Morphology. ACS Nano. 11:7807-20

43. Tsuji K, Păunescu TG, Suleiman H, Xie D, Mamuya FA, et al. 2017. Re-characterization of the Glomerulopathy in CD2AP Deficient Mice by High-Resolution Helium Ion Scanning Microscopy. Sci. Rep. 7:8321

44. Tsuji K, Suleiman H, Miner JH, Daley JM, Capen DE, et al. 2017. Ultrastructural Characterization of the Glomerulopathy in Alport Mice by Helium Ion Scanning Microscopy (HIM). Sci. Rep. 7:11696

45. Sato C, Sato M, Ogawa S, Sato M, Ogawa S, Ogawa S. 2018. Imaging of immunogold labeling in cells and tissues by helium ion microscopy. Int. J. Mol. Med. 42(1):309-21

46. Georgina Herrera M, Pizzuto M, Lonez C, Rott K, Hütten A, et al. 2018. Large supramolecular structures of 33-mer gliadin peptide activate toll-like receptors in macrophages. Nanomedicine Nanotechnology, Biol. Med. 14:1417-27

47. De Souza W, Attias M. 2018. New advances in scanning microscopy and its application to study parasitic protozoa. Exp. Parasitol. 190:10-33

48. de Souza W, Attias M. 2015. New views of the Toxoplasma gondii parasitophorous vacuole as revealed by Helium Ion Microscopy (HIM). J. Struct. Biol. 191(1):76-85

49. Leppänen M, Sundberg L-R, Laanto E, de Freitas Almeida GM, Papponen P, Maasilta IJ. 2017. Imaging Bacterial Colonies and Phage-Bacterium Interaction at Sub-Nanometer Resolution Using Helium-Ion Microscopy. Adv. Biosyst. 1:1700070

50. Boseman A, Nowlin K, Ashraf S, Yang J, LaJeunesse D. 2013. Ultrastructural analysis of wild type and mutant Drosophila melanogaster using helium ion microscopy. Micron. 51:26-35

51. Kim K-W. 2012. Helium Ion Microscopy of Uncoated Pine Leaves. Appl. Microsc. 42(3):147-50

52. Boden SA, Asadollahbaik A, Rutt HN, Bagnall DM. 2012. Helium ion microscopy of 
Lepidoptera scales. Scanning. 34(2):107-20

53. Gadelha APR, Benchimol M, de Souza W. 2015. Helium ion microscopy and ultra-highresolution scanning electron microscopy analysis of membrane-extracted cells reveals novel characteristics of the cytoskeleton of Giardia intestinalis. J. Struct. Biol. 190(3):271-78

54. Bidlack FB, Huynh C, Marshman J, Goetze B. 2014. Helium ion microscopy of enamel crystallites and extracellular tooth enamel matrix. Front. Physiol. 5:395

55. Byrne JM, Schmidt M, Gauger T, Bryce C, Kappler A. 2018. Imaging Organic-Mineral Aggregates Formed by Fe(II)-Oxidizing Bacteria Using Helium Ion Microscopy. Environ. Sci. Technol. Lett. 5:209-13

56. de Almeida FF, Santos-Silva EN, Ector L, Wetzel CE. 2018. Eunotia amazonica sp. nov. (Bacillariophyta), a common stalk-forming species from the Rio Negro basin (Brazilian Amazon). Eur. J. Phycol. 53(2):166-79

57. Valeri S. 1993. Auger electron emission by ion impact on solid surfaces. Surf. Sci. Rep. 17:85150

58. Benazeth N, Agusti J, Benazeth C, Mischler J, Viel L. 1976. Electronic emission from solid targets bombarded by noble gas ions (10-100 keV): Energetic and spatial distributions. Nucl. Instruments Methods. 132:477-82

59. Polak M. 1995. Ion-excited low-energy Auger electron emission from Ti and TiNi. J. Phys. Condens. Matter. 7:5275-79

60. Whaley R, Thomas EW. 1984. Auger spectra induced by $\mathrm{Ne}+$ and $\mathrm{Ar}+$ impact on $\mathrm{Mg}, \mathrm{Al}$, and $\mathrm{Si}$ . J. Appl. Phys. 56:1505

61. Xu F, Riccardi P, Oliva A, Bonanno A. 1993. Ar L-shell and metal M-shell Auger electron emission for $14 \mathrm{keV} \mathrm{Ar+} \mathrm{ion} \mathrm{impact} \mathrm{on} \mathrm{Ca}, \mathrm{Sc}, \mathrm{Ti}, \mathrm{V}, \mathrm{Cr}, \mathrm{Fe}, \mathrm{Co}, \mathrm{Ni}$, and $\mathrm{Cu}$. Nucl. Instruments Methods Phys. Res. Sect. B. 78:251-54

62. Parvaneh H. 2014. A new route to nanoscale tomographic chemical analysis: Focused ion beam-induced auger electron spectrosocpy. Rensselaer Polytechnic Institute

63. Parvaneh H, Hull R. 2014. Examination of ion-induced Auger electron spectra of $\mathrm{Ti}, \mathrm{Cr}$ and Co in a mass-selecting Focused Ion Beam with a gold-silicon liquid metal source. Vacuum. 110:69-73

64. Heller R, Klingner N, Hlawacek G. 2016. Backscattering Spectrometry in the Helium Ion Microscope: Imaging Elemental Compositions on the nm Scale. , pp. 265-95

65. Bell DC. 2009. Contrast Mechanisms and Image Formation in HIM. Microsc. Microanal. $15: 147-53$

66. Hlawacek G, Ahmad I, Smithers MA, Kooij ES. 2013. To see or not to see: Imaging surfactant coated nano-particles using HIM and SEM. Ultramicroscopy. 135:89-94

67. Sijbrandij S, Thompson B, Notte J, Ward BW, Economou NP. 2008. Elemental analysis with the helium ion microscope. J. Vac. Sci. Technol. B. 26(6):2103-6

68. Sijbrandij S, Notte J, Scipioni L, Huynh C, Sanford C. 2010. Analysis and metrology with a focused helium ion beam. J. Vac. Sci. Technol. B. 28(1):73-77

69. Klingner N, Heller R, Hlawacek G, Borany J von, Notte J, et al. 2016. Nanometer scale elemental analysis in the helium ion microscope using time of flight spectrometry. 
Ultramicroscopy. 162:

70. Hlawacek G, Veligura V, Lorbek S, Mocking TF, George A, et al. 2012. Imaging ultra thin layers with helium ion microscopy: Utilizing the channeling contrast mechanism. Beilstein J. Nanotechnol. 3(1):507-12

71. Veligura V, Hlawacek G, Van Gastel R, Zandvliet HJW, Poelsema B, et al. 2012. Channeling in helium ion microscopy: Mapping of crystal orientation. Beilstein J. Nanotechnol. 3(1):501-6

72. Veligura V, Hlawacek G. 2016. Ionoluminescence. , pp. 325-51

73. Franklin TMW. 2012. Scanning lonoluminescence Microscopy with a Helium Ion Microscope. University of Southampton. 198 pp.

74. Boden SA, Franklin TMW, Scipioni L, Bagnall DM, Rutt HN. 2012. lonoluminescence in the helium ion microscope. Microsc. Microanal. 18:1253-66

75. Veligura V, Hlawacek G, Van Gastel R, Zandvliet HJW, Poelsema B. 2015. Investigation of ionoluminescence of semiconductor materials using helium ion microscopy. J. Lumin. 157:321-26

76. Ogawa S, lijima T, Awata S, Sugie R, Kawasaki N, Otsuka Y. 2012. Characterization of Damage in $\mathrm{SiO} 2$ during Helium Ion Microscope Observation by Luminescence and TEM-EELS. Microsc. Microanal. 18, Issue:814-15

77. Veligura V, Hlawacek G, Gastel R V, Zandvliet HJW, Poelsema B. 2014. A high resolution ionoluminescence study of defect creation and interaction. J. Phys. Condens. Matter. 26(16):165401

78. Veligura V. 2014. Material Characterization and Modification using Helium Ion Microscopy: Various Examples. University of Twente. 114 pp.

79. Minqin R, Xiao C, Yi Z, Hao S, Qingguang R, et al. 2013. Sub-100-nm STIM imaging and PIXE quantification of rare earth elements in algae cells. $X$-Ray Spectrom. 42(4):237-41

80. Watt F, Chen X, Chen C-BB, Udalagama CNB, Van Kan JA, Bettiol AA. 2013. Whole cell structural imaging at 20 nanometre resolutions using $\mathrm{MeV}$ ions. Nucl. Instruments Methods Phys. Res. B. 306(0):6-11

81. Hall AR. 2013. In Situ Thickness Assessment During Ion Milling of a Free-Standing Membrane Using Transmission Helium Ion Microscopy. Microsc. Microanal. 19:740-44

82. Emmrich D, Beyer A, Nadzeyka A, Bauerdick S, Meyer JC, et al. 2016. Nanopore fabrication and characterization by helium ion microscopy. Appl. Phys. Lett. 108:163103

83. Woehl TJ, White RM, Keller RR. 2016. Dark-Field Scanning Transmission Ion Microscopy via Detection of Forward-Scattered Helium Ions with a Microchannel Plate. Microsc. Microanal. 22:544-50

84. Kavanagh KL, Herrmann C, Notte J. 2017. Camera for transmission He+ ion microscopy. J. Vac. Sci. Technol. B. 35:1-5

85. Notte J, Hill R, McVey SM, Ramachandra R, Griffin B, Joy D. 2010. Diffraction Imaging in a He+ Ion Beam Scanning Transmission Microscope

86. Wang J, Huang SH, Herrmann C, Scott SA, Schiettekatte F, Kavanagh KL. 2018. Focussed helium ion channeling through Si nanomembranes. J. Vac. Sci. Technol. B. 36:1-5 
87. Stehling N, Masters R, Zhou Y, O'Connell R. 2018. New perspectives on nano-engineering by secondary electron spectroscopy in the helium ion and scanning electron microscope. MRS Commun. 8(2):226-40

88. Masters RC, Pearson AJ, Glen TS, Sasam F-C, Li L, et al. 2015. Sub-nanometre resolution imaging of polymer-fullerene photovoltaic blends using energy-filtered scanning electron microscopy. Nat. Commun. 6:1-9

89. Kursheed A. 2011. Scanning Electron Microscope Optics and Spectrometers. World Scientific Publishing Co. Pte. Ltd.

90. Wirtz T, Vanhove N, Pillatsch L, Dowsett D, Sijbrandij S, Notte J. 2012. Towards secondary ion mass spectrometry on the helium ion microscope: An experimental and simulation based feasibility study with $\mathrm{He}+$ and $\mathrm{Ne}+$ bombardment. Appl. Phys. Lett. 101:041601

91. Pillatsch L, Vanhove N, Dowsett D, Sijbrandij S, Notte J, Wirtz T. 2013. Study and optimisation of SIMS performed with $\mathrm{He}+$ and $\mathrm{Ne}+$ bombardment. Appl. Surf. Sci. 282(0):908-13

92. Benninghoven A, Werner HW, Rüdenauer FG. 1987. Secondary ion mass spectrometry: Basic concepts, instrumental aspects, applications and trends

93. Franzreb K, Lörincik J, Williams P. 2004. Quantitative study of oxygen enhancement of sputtered ion yields. I. Argon ion bombardment of a silicon surface with $\mathrm{O} 2$ flood. Surf. Sci. 573(2):291-309

94. Philipp P, Wirtz T, Migeon H-N, Scherrer H. 2006. SIMS analysis with neutral cesium deposition: Negative secondary ion sensitivity increase and quantification aspects. Int. J. Mass Spectrom. 253(1-2):

95. Philipp P, Wirtz T, Migeon H-N, Scherrer H. 2006. Important increase of negative secondary ion sensitivity during SIMS analysis by neutral cesium deposition. Appl. Surf. Sci. 252(19):

96. Wirtz T, Migeon H-N. 2004. Optimization of SIMS analyses performed in the MCsX+ mode by using an in situ deposition of neutral Cs. Surf. Sci. 557:57-72

97. Wirtz T, Migeon H-N. 2004. In situ deposition of neutral Cs for Secondary lon Mass Spectrometry. Appl. Surf. Sci. 222(1-4):

98. Wirtz T, Dowsett D, Philipp P. 2016. SIMS on the Helium Ion Microscope: A Powerful Tool for High-Resolution High-Sensitivity Nano-Analytics. In Helium Ion Microscopy, ed G Hlawacek, A Golzhäuser, pp. 297-323. Springer Berlin / Heidelberg

99. Wirtz T, Philipp P, Audinot J-N, Dowsett D, Eswara S. 2015. High-resolution high-sensitivity elemental imaging by secondary ion mass spectrometry: From traditional 2D and 3D imaging to correlative microscopy. Nanotechnology. 26(43):

100. Gratia P, Grancini G, Audinot J-N, Jeanbourquin X, Mosconi E, et al. 2016. Intrinsic Halide Segregation at Nanometer Scale Determines the High Efficiency of Mixed Cation/Mixed Halide Perovskite Solar Cells. J. Am. Chem. Soc. 138(49):15821-24

101. Dowsett D, Wirtz T. 2017. Co-Registered In Situ Secondary Electron and Mass Spectral Imaging on the Helium Ion Microscope Demonstrated Using Lithium Titanate and Magnesium Oxide Nanoparticles. Anal. Chem. 89:8957-65

102. Philipp P, Rzeznik L, Wirtz T. 2016. Numerical investigation of depth profiling capabilities of helium and neon ions in ion microscopy. Beilstein J. Nanotechnol. 7(1):1749-60 
103. Rzeznik L, Fleming Y, Wirtz T, Philipp P. 2016. Experimental and simulation-based investigation of $\mathrm{He}, \mathrm{Ne}$ and $\mathrm{Ar}$ irradiation of polymers for ion microscopy. Beilstein J. Nanotechnol. 7:1113-28

104. Gratia P, Zimmermann I, Schouwink P, Yum J-H, Audinot J-N, et al. 2017. The Many Faces of Mixed Ion Perovskites: Unraveling and Understanding the Crystallization Process. ACS Energy Lett. 2(12):

105. Liu Y, Collins L, Proksch R, Kim S, Watson BR, et al. 2018. Chemical nature of ferroelastic twin domains in $\mathrm{CH} 3 \mathrm{NH} 3 \mathrm{~Pb} 3$ perovskite. Nat. Mater.

106. Fizesan I, Gutleb AC, Cambier S, Moschini E, Serchi T, et al. In vitro exposure of a 3Dtetraculture representative for the alveolar barrier at the air-liquid interface to silver particles and nanowires. Submitt. Part. Fibre Toxicol.

107. Vollnhals F, Audinot J-N, Wirtz T, Mercier-Bonin M, Fourquaux I, et al. 2017. Correlative Microscopy Combining Secondary Ion Mass Spectrometry and Electron Microscopy: Comparison of Intensity-Hue-Saturation and Laplacian Pyramid Methods for Image Fusion. Anal. Chem. 89(20):

108. Fleming $Y$, Wirtz T. 2015. High sensitivity and high resolution element 3D analysis by a combined SIMS-SPM instrument. Beilstein J. Nanotechnol. 6(1):

109. Wirtz T, Fleming Y, Gysin U, Glatzel T, Wegmann U, et al. 2013. Combined SIMS-SPM instrument for high sensitivity and high-resolution elemental 3D analysis. Surf. Interface Anal. 45(1):

110. Fleming Y, Wirtz T, Gysin U, Glatzel T, Wegmann U, et al. 2011. Three dimensional imaging using secondary ion mass spectrometry and atomic force microscopy. Appl. Surf. Sci. 258(4):

111. Vollnhals F, Wirtz T. Correlative Microscopy in 3D: HIM-based Photogrammetric Topography Reconstruction combined with HIM-SIMS. Anal. Chem.

112. Giannuzzi LA, Gorman BP. 2009. Particle-induced x-ray emission in stainless steel using $30 \mathrm{keV}$ $\mathrm{Ga}(+)$ focused ion beams. J. Vac. Sci. Technol. A. 27(4):668-71

113. Dyson NA. 1990. X-rays in Atomic and Nuclear Physics. Cambridge University Press 